\title{
Structural Analysis of an Articulated Urban Bus Chassis via FEM: a Methodology Applied to a Case Study
}

\author{
Dario Croccolo* - Massimiliano De Agostinis - Nicolò Vincenzi \\ DIEM, Department of Mechanical Engineering, University of Bologna, Italy
}

This paper deals with the static structural analysis of an articulated urban bus chassis, carried out with the Finite Elements Method. The purpose of this work is to simulate and forecast the structural response of the chassis, in terms of stress, strain and displacement, under several loading and constraining conditions, which aim at reflecting the actual duty cycle of the bus. A thorough interaction with the customer company allowed the authors to adequately define the loading scheme and to constrain the structure properly. Sensitivity analyses about FEM parameters have been run, in order to achieve an adequate trade off between computational time and results accuracy. Obtained results have been double checked by employing both solid (3D) and shell (2D) elements for each simulation. Eventually, the customer has been notified of critical issues and the related suggested improvements.

(C)2011 Journal of Mechanical Engineering. All rights reserved.

Keywords: bus, structure, frame, chassis, case study

\section{INTRODUCTION}

The vehicle under investigation is an articulated bus characterized by a length of 18 $\mathrm{m}$, realised by the joining of two chassis (Fig. 1), capable of carrying up to 160 passengers and with a mass at full load of about $30,000 \mathrm{~kg}$. Urban buses, as most part of passenger vehicles, are built around a tubular chassis that bears both the weight of the vehicle itself and the weight of passengers and luggage.

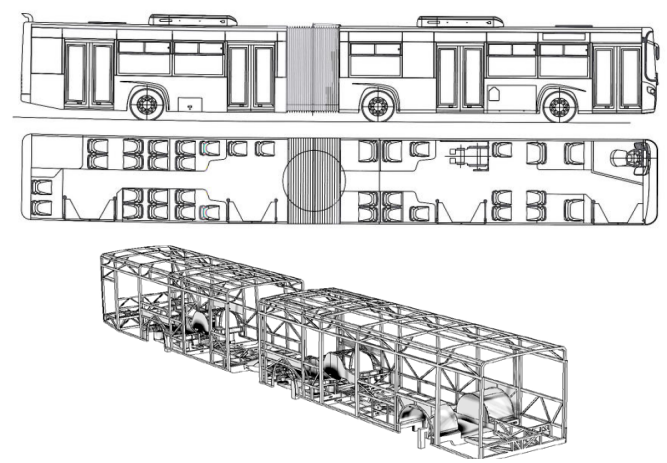

Fig.1. Urban bus and respective chassis

A good chassis shall also meets precise stiffness requirements in order to allow a safe drive under the most diverse traffic conditions. The chassis is realized by means of rectangular section tubular beams (Fig. 1), having external dimensions within the range of 30 to $150 \mathrm{~mm}$ and wall thicknesses within the range of 2 to $8 \mathrm{~mm}$, joined each other by full welding; several added bent sheets-ribs increase the overall assembly stiffness. A structural steel with a Young's modulus $E=200 \mathrm{GPa}$, a Poisson's ratio $v=0.3$, a yield stress $\mathrm{Sy}=400 \mathrm{MPa}$ and a mass density $\rho=7,850$ $\mathrm{kg} / \mathrm{m}^{3}$ has been employed. Modern FEM analysis capabilities, mainly in terms of computational resources, allow the vehicle manufacturer to fix structural issues before performing field tests, hence shortening the overall design and engineering phase, as demonstrated in [1] to [4]. Despites of the noticeable size of the chassis, the single beam used to realize the chassis is generally no longer than $1.5 \mathrm{~m}$. Moreover, the displacements object of investigation are several orders of magnitude smaller than the overall dimensions of the chassis. Therefore, an accurate choice of both the finite elements size and the contact elements definition is necessary. The analysis is limited to the sprung part of the vehicle: it is fundamental to remember that when the bus is performing a cornering manoeuvre, the centripetal accelerationforce given by the contact between asphalt and tyres together with the inertia forces acting on the body, make the suspension springs outside the curve compress, while those on the opposite side stretch. This results in a rolling movement of the vehicle body, which must be taken into account even when performing a static analysis, because the gravitational and inertia forces generate

*Corr. Author's Address: DIEM - Facoltà di Ingegneria,

Viale Risorgimento 2, 40136 Bologna, Italia, dario.croccolo@unibo.it 
different stress/strain distributions within the structure depending on its position with respect to a system of coordinates which is fixed to the ground, as suggested in [5]. Such behaviour could be well simulated by a bus model, which included the whole suspensions group [6].

\section{PRELIMINARY REMARKS}

The top level assembly of the chassis consists of about 1,500 parts, which belong to sub-structures representing, for instance, the floor, the roof and the body sides of the chassis. Due to hardware limitations, it would be impossible to analyze the whole structure (Fig. 1) at one time, hence the overall assembly has been divided into two sub assemblies, one being the front half of the chassis and one the rear part of it: from now on, they will be respectively referred to as A-chassis and B-chassis. Such a large structures would be generally analyzed by introducing rough approximations mainly concerning the loading and constraining hypotheses (uniform loads distributions [7]) or by means of beam (1D) elements [8].

The A-chassis, whose two front wheels are steering while the rear ones are fixed, comprehends the pilot's station: two passengers doors open on the right side of this chassis. A half part of the articulation system (the device that joins the two halves of the bus allowing them to rotate respectively around the vertical axis), is installed by the rear side of the A-chassis.

The B-chassis has only two wheels on the rear and hangs on the A-chassis by means of the other part of the articulation system. This chassis has no steering devices but it carries the engine group on the rear left side: two passengers doors are on the right side. Each chassis has been analyzed under six different loading and constraining schemes (cases), which aimed at simulating the chassis behaviour under the following conditions:

(a) the action of gravitational acceleration;

(b) the braking at the upper deceleration limit of the vehicle;

(c) the both sides cornering manoeuvres at the capsizing limit;

(d) the both sides torsion due to uneven road surface.
A Cartesian Coordinate System has been chosen [5] with its origin into centre of the articulation system: $\mathrm{X}$-axis is oriented as the driving gear, Z-axis is pointing upwards and Y-axis follows the right hand rule.

\section{FEA SETUP}

The main structural elements of steel framed structures (e.g. the bus chassis, Fig. 1) have to be studied as the assembly of three different components, namely, columns, beam and their joints (Fig. 2).

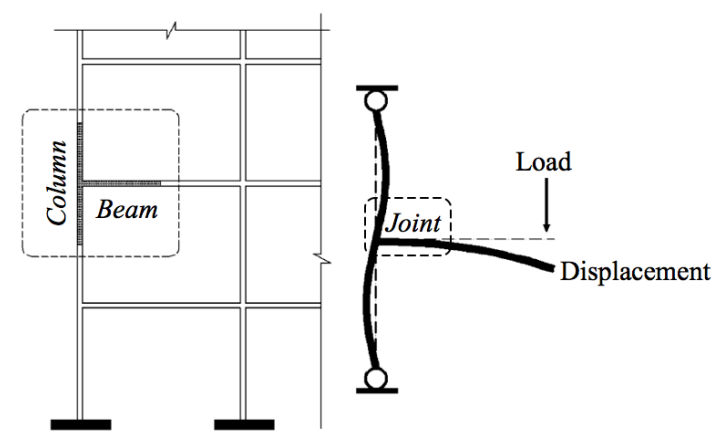

Fig. 2. Example of steel framed structure: main structural components (column, beam and joint)

The capacity of steel frames to resist loads is determined more by the strength and, in particular, the stiffness of the joints than by the properties of the members themselves [9]. In practice, beam-to-column joints in conventional analysis and design of steel frameworks are usually assumed to behave either ideally pinned or fully rigid. Conversely, experimental investigations [10] show that the true behaviour of joints lies in between that of ideally compliant and fully rigid: such joints are referred to as semi-rigid joints. Overestimating the joint stiffness may result in underestimating the forces developed in beam and column and the overall displacement of the global frame structure. Neglecting the real behaviour of the joint may lead to unrealistic predictions of the response and reliability of steel frames [11]: both of these extreme assumptions are inaccurate and uneconomic. When approaching the problem by a numerical (FEM) standpoint the latter issues occur in formulating the contact parameters between two or more structural members. When dealing with contacts there is a lot more to control 
than the mesh size type [12] and in particular the contact formulation as well as the contact stiffness parameters. Finite Elements Analyses have been performed by means of the Ansys Code, Workbench Release 12. In order to manage the contact formulation, the Augmented Lagrangian Method has been chosen as it allows, by manually setting the contact stiffness parameters, a better approximation of the interactions occurring within the contact areas of welded structures. As a matter of fact the Augmented Lagrangian is an iterative method working by two consequent steps: firstly, like a simple Penalty Method, locally modifying the bodies' normal stiffness in the contact region until the equilibrium is satisfied. Then, if any interference (penetration) occurred, it proceeds adding a convenient pressure to the mating surfaces, until the interference is overridden. The contact stiffness parameter (normal or tangential) can be input as an absolute value ( $K N$ or $K T)$ or as a factor ( $F K N$ or $F K T)$ to the default Hertz contact stiffness $K H$, which depends on the component geometry and material. For surface-to-surface contact elements, Ref. [13] recommends a FKN value in the range from 0.001 to 100 (default value 1.0): changes in such range strongly affect the solution in terms of stresses, strains and displacements. $F K N$ value shall be tuned by means of experimental analyses. Experimental results on a full welded T-joint, comparable in dimensions and welding method to that used on the bus chassis (Fig. 3), have been obtained by Yang and Kim [10].

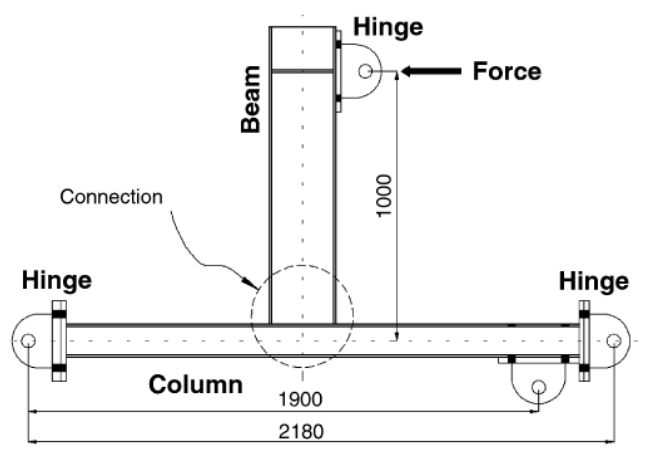

Fig. 3. Full welded T-joint specimen tested in [9]

In particular, they established that under the maximum force (for the linear elastic field) of $42.1 \mathrm{kN}$ applied to the upper hinge a deflection of $12 \mathrm{~mm}$ occurs at the same point. Numerical results in terms of upper beam displacements as a function of the $F K N$ parameter are reported in Table 1 and shown in Fig. 4: a $F K N$ value between 0.01 and 0.005 offers a reliable prediction of experimental results.

Table 1. FEA displacements as a function of the FKN parameter

\begin{tabular}{|c|c|}
\hline \multicolumn{2}{|c|}{ Experimental displacement $\approx \mathbf{1 2} \mathbf{~} \mathbf{m m}[9]$} \\
\hline $\begin{array}{c}\text { FKN - Normal Stiffness } \\
\text { Factor }\end{array}$ & $\begin{array}{c}\text { FEA displacement } \\
{[\mathrm{mm}]}\end{array}$ \\
\hline Default $(1.0)$ & 8.13 \\
\hline 0.1 & 8.51 \\
\hline 0.05 & 8.80 \\
\hline $\mathbf{0 . 0 1}$ & $\mathbf{1 0 . 6 8}$ \\
\hline $\mathbf{0 . 0 0 5}$ & $\mathbf{1 2 . 7 0}$ \\
\hline 0.001 & 26.82 \\
\hline
\end{tabular}
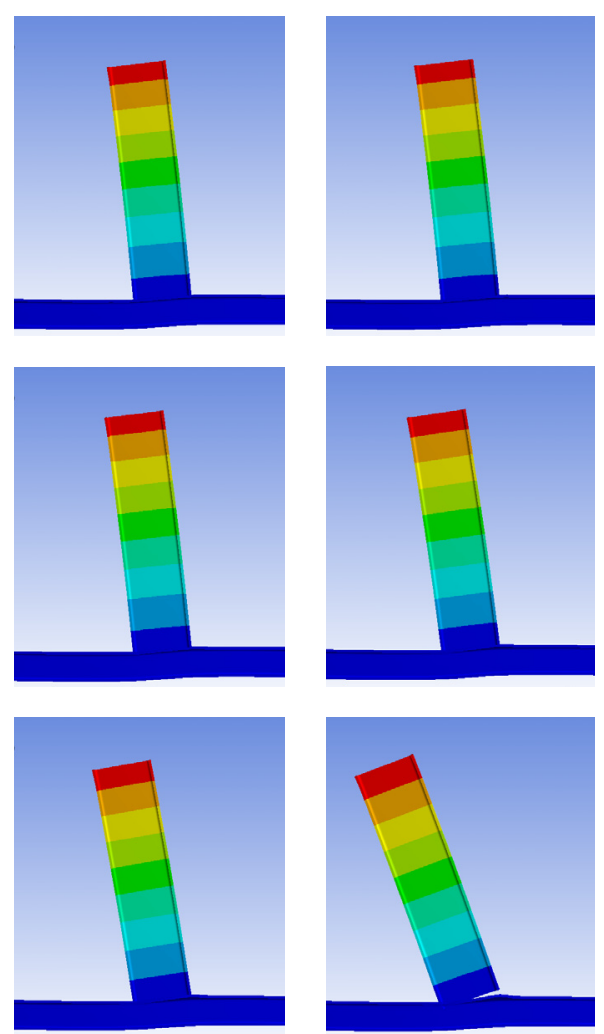

Fig. 4. Deformed shape $(14 \times$ magnification $)$ of the T-joint specimen tested in [9] as a function of the contact normal stiffness factor FKN in Table 1

The evaluation of the tensile state in the vicinity of the weld toe (e.g. hot spot stress method 
or the peak stress method recently proposed by Meneghetti et al. [14]) is not the object of this work. No welds are, accordingly, modelled in the chassis geometry; the connection between beam and column is managed by the contact stiffness parameters, as shown in [8]. In order to check the numerical structural stress state of the beam and column (far from the weld toe), a comparison with the data evaluated via strain gages in a square-tosquare hollow section T-joint [14] and [15], has been performed. Both solid (3D) mesh and shell (2D) mesh have been compared to the results obtained in the reference geometry reported in Fig. 5 [14] and [15].

The applied loads are reported in Fig. 5, while the stress results (in terms of maximum principal stress as suggested by the peak stress method [14]) in Fig. 6. An attentive examination of the results shows that at a distance almost equal to the cross section dimensions (dashed lines) the stresses evaluated both via $3 \mathrm{D}$ mesh and via $2 \mathrm{D}$ mesh (without modeling the weld) converged to the reference one [14] and [15].
As suggested in [16], tubular joints have been meshed by using shell (2D) elements that represent the mid-surfaces of the joint member walls. As shown previously and as accurately demonstrated in [17], the results are perfectly comparable with the ones obtained by means of a solid (3D) mesh: the second technique is still ten times more demanding than the first in terms of disk space.

\section{FEA LOADING CASES}

Each load applied to the A-chassis as well as to the B-chassis has been introduced as a lumped mass. These masses undergo acceleration components imposed by the conditions described in Section 1, and are attached to one or more surfaces belonging to one or more chassis components. Using lumped masses rather than remote forces results in a speed up of the workflow when the boundary conditions have to be changed. For example, the gravitational acceleration can
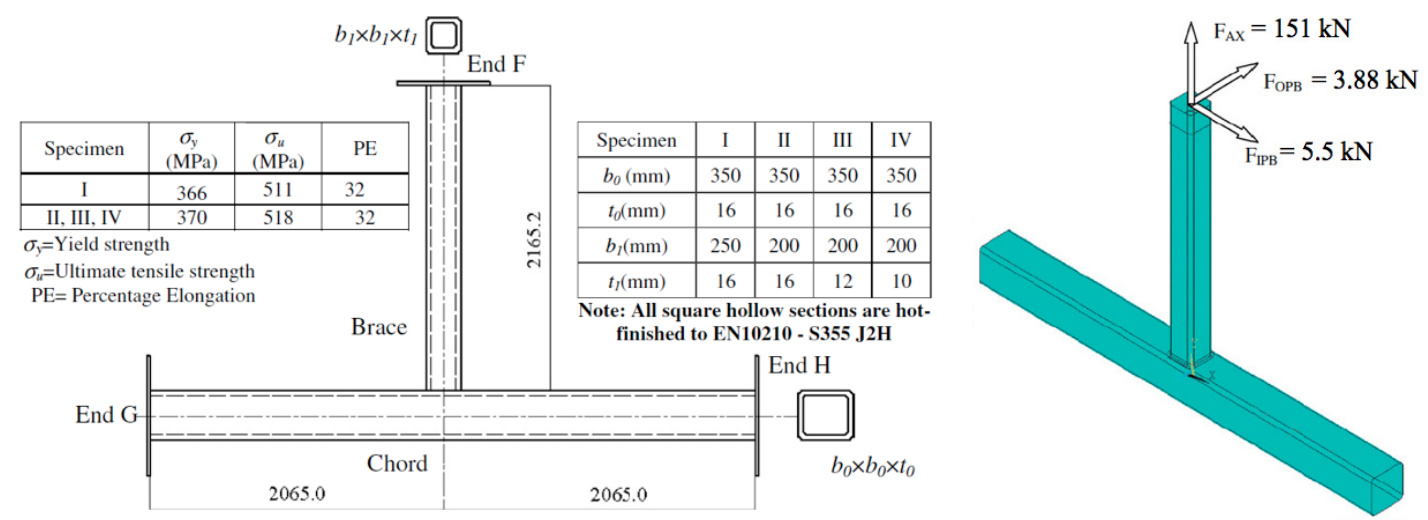

Fig. 5. The square-to-square hollow section T-joint specimen tested in [13] and [14]

a)

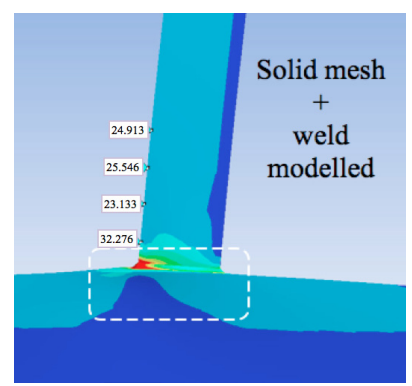

b)

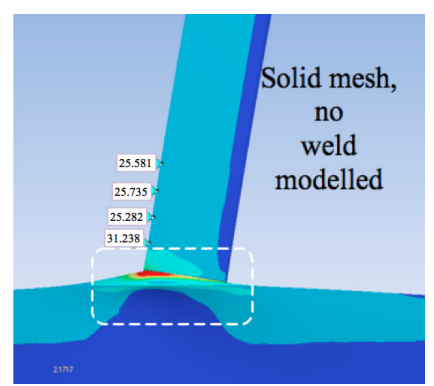

c)

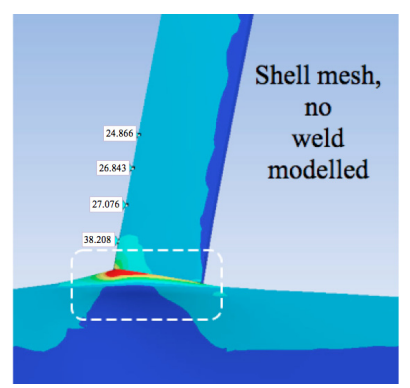

Fig. 6. Comparison in stress distributions (deformed shape 50x magnification) far from the joint between beam and column (dashed lines); a) reference geometry [13] and [14] with the welded joint modelled, b) solid mesh without the weld, c) shell mesh without the weld; mesh size: $1 \mathrm{~mm}$ 
be quickly changed into the forward or lateral accelerations acting on the system.

For remote boundaries conditions, such as the lumped masses defined, Ansys allows the control of the specific geometry behaviour, which can be defined as either rigid or deformable. A deformable behaviour has been chosen here by the authors, as it represents the actual response of the structure well: in fact, on the other hand, the masses application areas would result in being unreasonably undeformable.

Since the B-chassis is attached to the A-chassis by means of an articulation device, the analyses on the B-chassis were carried out first, assuming the constraints between the B-chassis and the A-chassis to be of the hinge type, and to be applied on the edges of the articulation device. Accordingly, when performing the corresponding analysis the reaction forces of the same magnitude evaluated on the articulation device were applied, but opposite in direction to the A-chassis.

The results in terms of total displacement and Von Mises equivalent stress distribution have been computed and analyzed for each condition.

Constraint reactions in magnitude and direction have been checked to be equal to the imposed loads in magnitude and direction as an overall verification of the simulation process.

\subsection{B-Chassis}

At first, lumped masses (represented as spheres) have been applied to the chassis. In Fig. 7, for instance, $2,950 \mathrm{~kg}$ of distributed masses belonging to coatings and body panels are shown: each sphere has the same color of its target parts. Masses related to onboard systems, windows and doors $(1,046 \mathrm{~kg})$ and those belonging to passengers' mass $(4,931 \mathrm{~kg})$ have been, instead, represented in Fig. 8. The 1,500 kg engine mass has been subdivided into three lumped masses: each of them has been applied to the relevant engine mount on the chassis. The B-chassis self weight is $1,658 \mathrm{~kg}$.

\subsubsection{B-Chassis, Gravitational Acceleration}

Fixed supports have been applied both to the rear axle edges and to the articulation device edges: this type of constraints, since applied to a line formed by a single edge, can be considered equivalent to an ideal hinge that locks rotational motions around $\mathrm{X}$-axis and $\mathrm{Z}$-axis and translation along each axis. Then, the standard gravitational acceleration $g\left(9.81 \mathrm{~m} / \mathrm{s}^{2}\right)$ has been applied to the whole mass system.

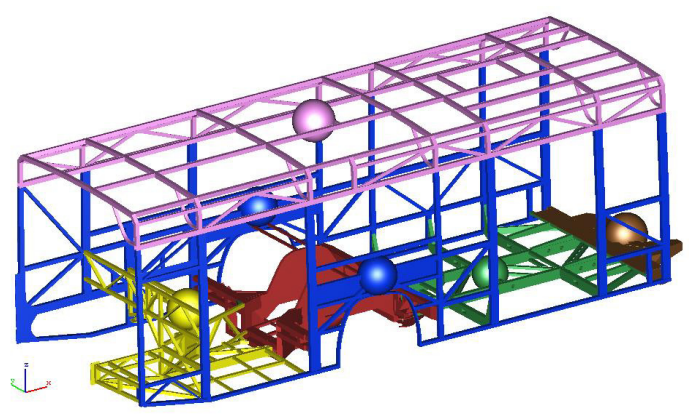

Fig. 7. B-chassis: example of distributed masses related to the main body structure

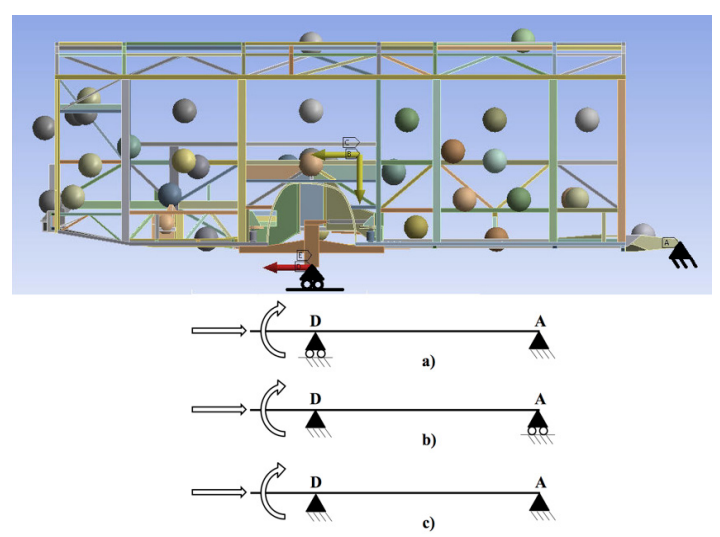

Fig. 8. B-chassis loads and constraints - loading case 3.1.2

\subsubsection{B-Chassis, Gravitational Acceleration and Braking Deceleration}

In order to simulate the effects of a severe brake, a $0.75 \cdot g$ acceleration [5] and [18] has been added along the positive $\mathrm{X}$ direction. The gravitational acceleration still acts on the system. Moreover, the rear axle edges constraints have been redefined according to Fig. 8, allowing them to translate only along $\mathrm{X}$-axis (Z-axis and Y-axis displacements are still equal to zero). At the same time, braking forces $F_{\mu}$ (Eq. (1)) have been applied to the lower edges of the rear axle (see Fig. 8, flag $\mathrm{D}$ and $\mathrm{E}$ ), by imposing the Coulomb friction law [18] to [20]: 


$$
F_{\mu}=\mu \cdot F_{Z r, B} .
$$

This hypothesis considers the rear wheels subjected to the braking force $F_{\mu}$, while the front articulation edges hold up the remaining $\mathrm{X}$-axis force $R_{x}$ given by Eq. (2) (Fig. 8a):

$$
R_{x}=m_{B-\text { chassis }} \cdot 0.75 \cdot g-F_{\mu} .
$$

Such a constraint scheme produces the highest stresses and displacements on the structure because the whole B-chassis is subjected to both the bending moment and the compression force generated by the inertial loads. Conversely, in the two remaining schemes (Figs. $8 \mathrm{~b}$ and c) loads and moments are partially supported by the rear constraint and, therefore, they are not affecting the central section of the frame.

Since $F_{Z r, B}$ changes during the brake depending on the load transfer from the rear axle to the front support [21] and [22], the correct $F_{Z r, B}$ value has been determined by some iterative analyses: firstly, the vertical constraint reaction on the rear axle are determined from the static equilibrium $\left(F_{Z r, B_{1}}\right)$ and the simulation has been run using $F_{\mu}=\mu \cdot F_{Z r, B_{-} 1}$, then the actual vertical constraint reactions on the rear axle $\left(F_{Z r, B_{-} 2}\right)$ has been calculated. A new simulation has been run again assuming $F_{\mu}=\mu \cdot F_{Z r, B \_2}$ and calculating the actual vertical constraint reactions on the rear axle $\left(F_{Z r, B}{ }_{3}\right)$. The same procedure of assuming $F_{\mu}=\mu \cdot F_{Z r, B_{-} i}$ and calculating the actual vertical constraint reactions $\left(F_{Z r, B} i+1\right)$ lasted until no significant discrepancy has been found between two subsequent values of $F_{Z r, B}\left(F_{Z r ; B_{-} i} \approx F_{Z r ; B_{-} i+1}\right)$.

\subsubsection{B-Chassis, Gravitational Acceleration and Cornering}

Since the chassis is not symmetric about XZ-plane (see Fig. 7), two simulations have been run in order to evaluate the effects of both right and left cornering manoeuvres performed on a plain ground. Since the standard gravitational acceleration is always present, an acceleration vector having a magnitude of $0.75 \cdot \mathrm{g}$ and directed along Y-axis, (positive or negative depending on the turning direction) has been added to the system. The constraints remain the same used for the brake simulation. It is important to verify that the rear axle reactions provided by the analysis exclude any capsizing tendency of the vehicle when subjected to this loading case: both of the rear constraints must have positive reactions along Z-axis.

\subsubsection{B-Chassis, Torsion}

The chassis could be subjected to torsion when, for example, the bus should run on an uneven asphalt mat. In order to recreate such a condition, two analyses have been performed, suppressing two of the total four constraints at a time and applying the sole standard gravitational acceleration. The supports to be suppressed have been chosen as follows: (i) left articulation constraint and right rear axle constraint; (ii) right articulation constraint and left rear axle constraint.

In this way, the chassis could twist around the axis that joints the remaining supports.

\subsection{A-Chassis}

Lumped masses were applied to this chassis and for the B-chassis: $2901 \mathrm{~kg}$ of distributed masses belonging to coatings and body panels, $494 \mathrm{~kg}$ related to windows and doors, $5822 \mathrm{~kg}$ belonging to passengers and the driver and 1540 $\mathrm{kg}$ related to relevant systems have beenw applied to the chassis. The A-chassis self weight is $\mathbf{2 2 5 2}$ $\mathrm{kg}$.

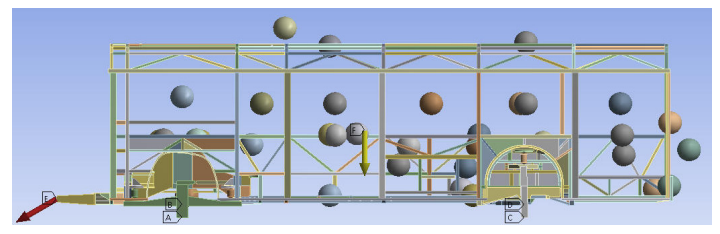

Fig. 9. A-chassis loads and constraints - loading case 3.2.1

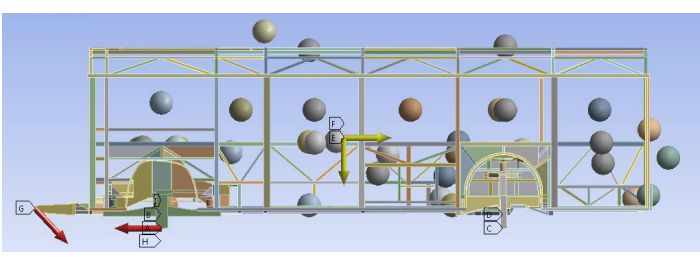

Fig. 10. A-chassis loads and constraints - loading case 3.2.2

As mentioned before, the reactions on the articulation device edges have beencarried over 
from the analyses performed on the B-chassis (opposite in direction), as shown in Figs. 9 and 10.

\subsubsection{A-Chassis, Gravitational Acceleration}

Fixed supports have been applied both to the rear and to the front axle edges: this type of constraints is equivalent to an ideal hinge locking rotational motions around $\mathrm{X}$-axis and $\mathrm{Z}$-axis and translation along each axis. The standard gravitational acceleration $g\left(9.81 \mathrm{~m} / \mathrm{s}^{2}\right)$ has been applied to the system.

\subsubsection{A-Chassis, Gravitational Acceleration and Braking Deceleration}

In order to simulate the effects of a severe brake, a $0.75 \cdot g$ acceleration has been added along the positive $\mathrm{X}$ direction. The gravitational acceleration still acts on the system. Moreover, braking forces have been applied to the lower edges of the rear axle, which have been allowed to translate along $\mathrm{X}$-axis, while the front axle edges have been locked towards the three components of translation. As for the B-chassis, such constraining hypotheses make the chassis working under the worst condition of free deflection length. Braking forces intensity defined by iteration, as was formerly done for the B-chassis.

\subsubsection{A-Chassis, Gravitational Acceleration and Cornering}

Since the chassis is not symmetric about XZ-plane (the passenger doors are located on the right side), two simulations have been run in order to evaluate the effects of both right and left cornering manoeuvres performed on a plain ground. The standard gravitational acceleration still acts on the system, together with an acceleration vector directed along Y-axis with a $0.75 \cdot g$ magnitude (positive or negative depending on the turning direction).

The constraints are still the same used for the brake simulation. The rear axle reactions provided by the analysis exclude any capsizing tendency of the vehicle when subjected to this loading case: in fact both of the rear constraints have positive reactions along $\mathrm{Z}$-axis.

\subsubsection{A-Chassis, Torsion}

Two torsion analyses have been performed also on the A-chassis by suppressing two of the four supports at a time and applying the standard gravitational acceleration. The supports to be suppressed have been chosen as follows:

(i) Left front axle constraint and right rear axle constraint;

(ii) Right front axle constraint and left rear axle constraint.

In this way, the chassis can twist around the axis that joints the remaining supports.

\section{FEA RESULTS AND DISCUSSION}

The sum of the external loads applied to the structure and the sum of the constraints reactions have been compared for each analysis in order to evaluate the overall equilibrium of the chassis and, therefore, exclude macroscopic errors affecting the results. The resume of such verification is reported in the Appendix at the end of the manuscript: the results are subdivided into four kinds of loading cases (vertical, braking, cornering, torsion) respectively, for the A-chassis and B-chassis in terms of constraints or external loads direction and magnitude. As shown in the Appendix, discrepancies are always lower than $0.3 \%$. A stress limit equal to $S_{1}=150 \mathrm{MPa}$ (safety factor of 2.6 with respect to the yield limit), has been chosen in accordance with the customer: the multiaxial stress states have been compared with the uniaxial material properties by means of the Von-Mises yield criterion. Even if static analyses have been performed, Meznar and Lazovic [23], Lan et al. [24] and Kim et al. [25] have demonstrated the importance of these preliminary FEA results for further experimental analyses (e.g. strain gauges as deep demonstrated in [23]) performed on typical duty cycles.

\subsection{A-Chassis}

The A-chassis has a good overall response to every imposed loading condition, since no significant area of it exceeded the established equivalent stress limit $S_{1}$. Braking and cornering conditions, according to [23], are the most severe because stresses show up close to $S_{1}$, interesting 


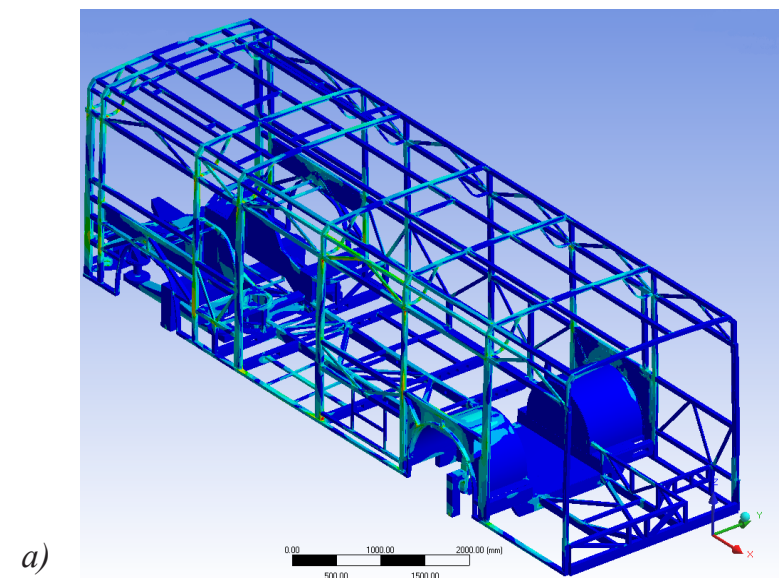

b)

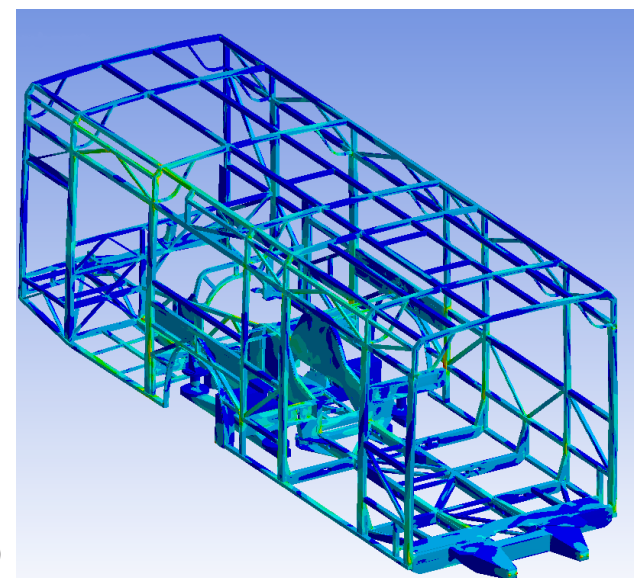

Fig. 11. Stress distributions in A (a) and B (b) chassis in most severe (cornering) loading condition

different areas depending on the loading case. Some chassis portions underneath the floor and close to the articulation device are impacted by the effects of braking with Von-Mises stress mean values of about $100 \mathrm{MPa}$ (Fig. 11a), essentially due to forces transmitted by the B-chassis via the articulation device itself. The right side pillars and the J-shaped tubular beams, which connect the roof to the right body side, have stress values of about $130 \mathrm{MPa}$ when the left-cornering loading case is applied. It is worth mentioning that stresses recorded in the right-cornering loading case are much lower than those of the left-cornering loading case only due to the left-side being stiffer than the right-side, as a consequence of a lack of door holes on the right.

The rooftop area has demonstrated to always have the greatest displacement values $\Delta$, differentiated as a function of the loading conditions: a magnitude of about 6 and $12 \mathrm{~mm}$ is reached when gravity and braking loading cases are applied, respectively. The peak values of about 24 and $18 \mathrm{~mm}$ are reached for cornering and for torsion respectively. The deformed shapes of the structure, due to the applied loads, are reported in Figs. 12 to 15, with an appropriate scale factor (20× magnification). As the performances in terms of stresses and displacements of the A-chassis have been judged to be compliant with the specifications, no structural improvement has been suggested to the customer.

\subsection{B-Chassis}

Left-cornering loading case (Fig. 11b) is the most severe condition for the B-chassis as well, causing wide areas of the tubular beam shown in Fig. 16a, which appreciably exceed the equivalent stress limit $\mathrm{Sl}$, as Von-Mises stresses on such component assume values close to $190 \mathrm{MPa}$. Indeed, such a beam had been noticed to be a critical component for all the loading cases since it has the highest stress values in the whole structure. Therefore, the original $3 \mathrm{~mm}$ thick beam has been replaced with a $5 \mathrm{~mm}$ thick one, and a new leftcornering simulation has been performed in order to validate the change. During the cornering manoeuvres the stress value on the body-side pillars results of about $140 \mathrm{MPa}$, as reported in Fig. 16b, which is now an adequate value: hence, the stress decrease for the proposed solution is equal to $26 \%$. Elsewhere, the B-chassis shows a fair behaviour, since stress and displacement remain beneath the established limits.

The maximum displacement values are located on the front left engine support $(\Delta=9$ $\mathrm{mm}$ ) when braking loads are applied (Fig. 13) and on the rooftop $(\Delta=11 \mathrm{~mm})$ when gravity loads are applied (Fig. 12). Eventually, during the cornering to the left (Fig. 14) a peak value of about $27 \mathrm{~mm}$ is reached on the rooftop, which becomes about 33 $\mathrm{mm}$ when torsion occurs (Fig. 15). As mentioned before some images of the deformed structure due to the different loading cases, are reported in Figs. 12 to 15 . 

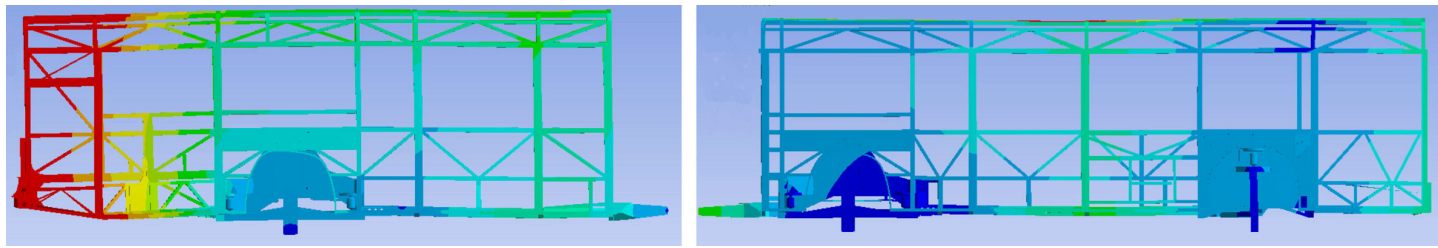

Fig. 12. Total displacements - gravity loading case
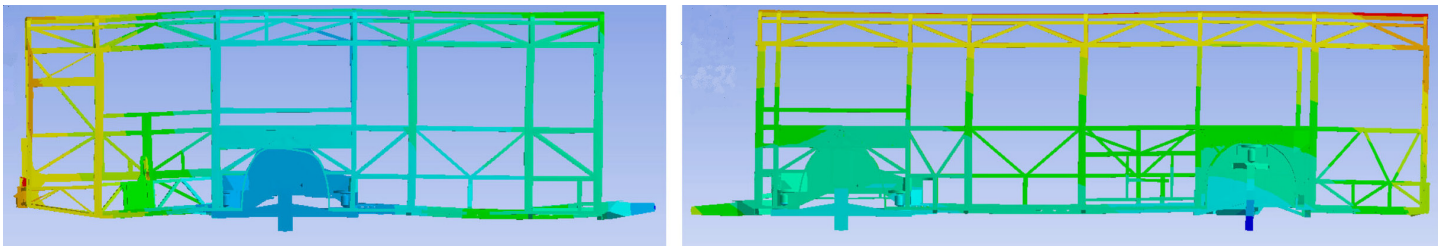

Fig. 13. Total displacements - braking loading case
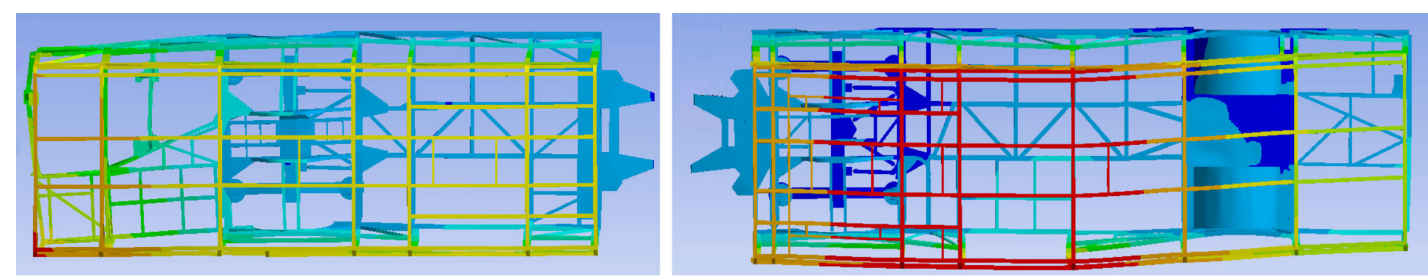

Fig. 14. Total displacements - left cornering loading case
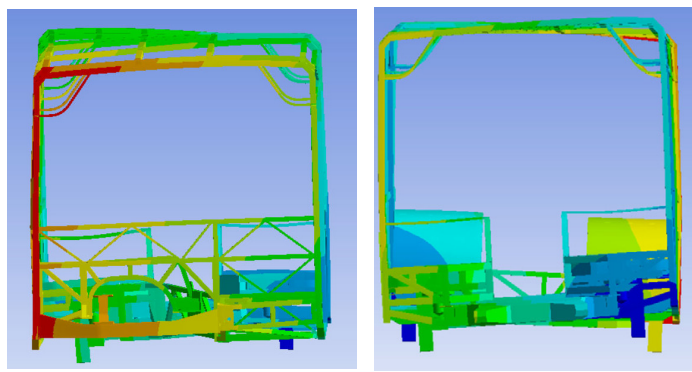

Fig. 15. Total displacements - Torsion loading case (scale factor $20 \times$ )

a)

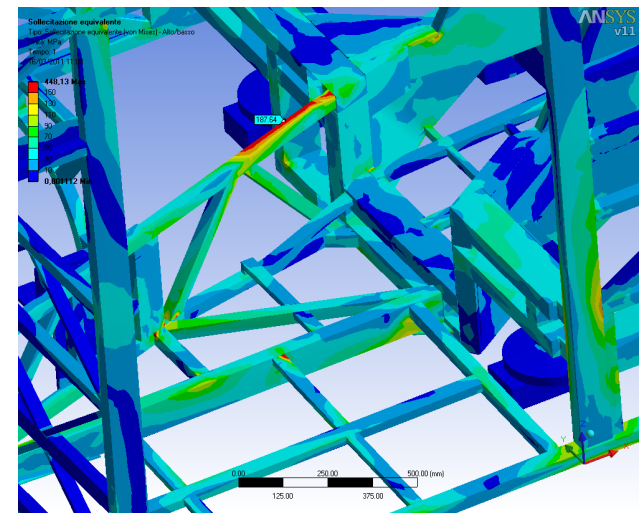

\section{CONCLUSIONS}

The static structural analysis of an articulated urban bus chassis, with a total length of $18 \mathrm{~m}$, has been performed via Finite Elements Method. The frame behaviour towards four different loading conditions, representative of its typical duty cycle, has been analysed: the action of gravitational acceleration, the braking at the upper deceleration limit of the vehicle, the cornering manoeuvres and the torsion due to uneven road

b)

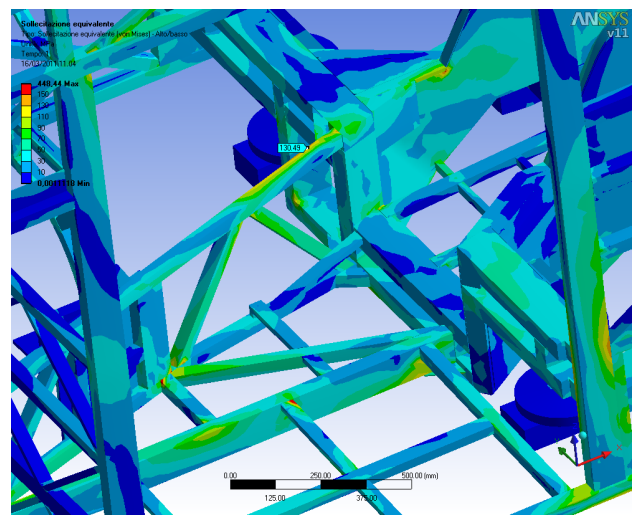

Fig. 16. Von-Mises equivalent stress values on the critical beam; a) original beam, b) modified beam 
surface. Sensitivity analyses in order to evaluate the welded joint performances have been carried out in order to obtain reliable results in terms of stiffness and displacements of the chassis (steel framed structure). Braking and cornering conditions have been demonstrated to be the most severe, especially on the B-Chassis (the rear one). Needful improvements have been suggested to the manufacturer in order to help achieve the target strength/stiffness characteristics on the whole structure.

\section{REFERENCES}

[1] Croccolo, D., Cuppini, R., Vincenzi, N. (2007). The design and optimization of forkpin compression coupling in front motorbike suspensions. Finite Elements in Analysis and Design, vol. 43, p. 977-988, DOI:10.1016/j. finel.2007.06.016.

[2] Croccolo, D., Cuppini, R., Vincenzi, N. (2009). Design improvement of clamped joints in front motorbike suspension based on FEM analysis. Finite Elements in Analysis and Design, vol. 45, p. 406-414, DOI:10.1016/j.finel.2008.11.007.

[3] Croccolo, D., De Agostinis, M., Vincenzi, N. (2010). Recent improvements and design formulae applied to front motorbike suspensions. Engineering Failure Analysis, vol. 17, p. 1173-1187, DOI:10.1016/j. engfailanal.2010.02.002.

[4] Croccolo, D., De Agostinis, M., Vincenzi, N. (2011). Failure analysis of bolted joints: effect of friction coefficients in torque preloading relationship. Engineering Failure Analysis, vol. 18, p. 364-373, DOI:10.1016/j. engfailanal.2010.09.015.

[5] ISO8855 (1991). Road vehicles Vehicle dynamics and road-holding ability. International Organization for Standardization, Geneva.

[6] Reimperl, J., Stoll, H., Betzler, J.W. (2001). The Automotive Chassis: Engineering Principles (2001), II Edition, SAE International, Warrendale.

[7] Larrodé, E., Miravete, A., Fernàndez, F.J. (1995). A new concept of a bus structure made of composite materials by using continuous transversal frames.
Composite Structures, vol. 32, p. 345-356, DOI:10.1016/0263-8223(95)00060-7.

[8] Gauchia, A., Diaz, V., Boada, M.J.L., Boada, B.L. (2010). Torsional stiffness and weight optimization of a real bus structure. International Journal of Automotive Technology, vol. 11, p. 41-47, DOI:10.1007/ s12239-010-0006-4.

[9] Elnashai, A.S., Elghazouli, A.Y. (2003). Seismic behaviour of semi-rigid steel frames. Journal of Constructional Steel Research, vol. 29, p. 149-174, DOI:10.1016/0143974X(94)90060-4.

[10] Yang, C.M., Kim, Y.M. (2007). Cyclic behaviour of bolted and welded beam-tocolumn joints. International Journal of Mechanical Science, vol. 49, p. 635-649, DOI:10.1016/j.ijmecsci.2006.09.022.

[11] Hadianfard, M.A., Razani, R. (2003). Effects of semi-rigid behaviour of connection in the reliability of steel frames. Structural Safety, vol. 25 , p. $123-138$, DOI:10.1016/S01674730(02)00046-2.

[12] Lanoue, F., Vadean, A., Sanschagrin, B. (2009). Finite element analysis and contact modelling considerations of interference fits for fretting fatigue strength calculations. Simulation Modelling Practice and Theory, vol. 17, p. 1587-1602, DOI:10.1016/j. simpat.2009.06.017.

[13] Ansys Theory Manual 12.0.

[14] Meneghetti, G., Atzori, B., Manara, G. (2010). The peak stress method applied to fatigue assessments of steel tubular welded joints subjected to mode I loading. Engineering Fracture Mechanics, vol. 77, p. 2100-2114, DOI:10.1016/j. engfracmech.2010.04.002.

[15] Chiew, S.P., Lee, C.K., Lie, S.T., Ji, H.L. (2007). Fatigue behaviors of square-tosquare hollow section T-joint with corner crack: experimental studies. Engineering Fracture Mechanics, vol. 74, p. 703-720, DOI:10.1016/j.engfracmech.2006.06.022.

[16] Lee, M.M.K. (1999). Strength, stress and fracture analyses of offshore tubular joints using finite elements. Journal of Constructional Steel Research, vol. $51, \quad$ p. 265-286, DOI:10.1016/S0143974X(99)00025-5. 
[17] Pey, L.P., Soh, A.K., Soh, C.K. (1995). Partial implementation of compatibility conditions in modeling tubular joints using brick and shell elements. Finite Elements in Analysis and Design, vol. 20, p. 127-138. DOI:10.1016/0168-874X(95)00020-T.

[18] ISO611 (2003). Road vehicles - Braking of automotive vehicles and their trailersVocabulary. International Organization for Standardization, Geneva.

[19] Pacejka, H. (2005). Tyre and Vehicle Dinamycs, Elsevier, Amsterdam.

[20] Watanabe, K., Yamakawa, J., Tanaka, M., Sasaki, T. (2007). Turning characteristics of multi-axle vehicles. Journal of Terramechanics, vol. 44, p. 81-87, DOI:10.1016/j.jterra.2006.01.007.

[21] Corno, M., Savaresi, S.M., Tanelli, M., Fabbri, L. (2008). On optimal motorcycle braking. Control Engineering Practice, vol. 16, p. 644-657. DOI:10.1016/j.conengprac.2007.08.001.
[22] Genta, G., Morello, L. (2002). The Automotive Chassis Vol. 1: Components design. Springer.

[23] Meznar, D., Lazovic, M. (2010). The strength of the bus structure with the determination of critical points. Strojniski vestnik - Journal of Mechanical Engineering, vol. 56, p. 544550.

[24] Lan, F., Chen, J., Lin, J. (2004). Comparative analysis for bus side structures and lightweight optimization. Proceedings of the Institution of Mechanical Engineers, Part D - Journal of Automobile Engineering, vol. 218, p. 1067-1075, DOI: $10.1177 / 095440700421801001$.

[25] Kim, M.H., Suh, M.W., Bae, D.H. (2001). Development of an optimum design technique for the bus window pillar member. Proceedings of the Institution of Mechanical Engineers, Part D - Journal of Automobile Engineering, vol. 215, p. 11-20, DOI:10.1243/0954407011525421.

\section{APPENDIX}

Here below the comparison between constraints reactions and applied external loads is reported: results are subdivided into the four kinds of loading cases, respectively for the A-chassis and B-chassis.

\begin{tabular}{|c|c|c|c|c|c|c|c|c|c|}
\hline \multicolumn{5}{|l|}{ A-chassis } & \multicolumn{5}{|l|}{ B-chassis } \\
\hline \multirow{3}{*}{$\begin{array}{l}\text { 3.2.1 GRAVITY ONLY } \\
\text { CONSTRAINT NAME }\end{array}$} & \multirow{3}{*}{ UNIT } & \multirow{2}{*}{\multicolumn{3}{|c|}{ DIRECTION }} & 3.1.1 GRAVITY ONLY & \multirow{3}{*}{ UNIT } & \multirow{2}{*}{\multicolumn{3}{|c|}{ DIRECTION }} \\
\hline & & & & & \multirow{2}{*}{ CONSTRAINT NAME } & & & & \\
\hline & & $\mathrm{X}$ & Y & Z & & & $\mathrm{X}$ & $\mathrm{Y}$ & $\mathrm{Z}$ \\
\hline LEFT FRONT & $\mathrm{N}$ & 1,554 & $-6,554$ & 31,199 & REAR AXLE & $\mathrm{N}$ & $-25,796$ & 1,185 & 103,090 \\
\hline RIGHT FRONT & $\mathrm{N}$ & 1,860 & 6,541 & 28,781 & ARTICULATION & $\mathrm{N}$ & 25,796 & $-1,185$ & 15,413 \\
\hline LEFT REAR & $\mathrm{N}$ & 11,363 & $-18,517$ & 42,098 & & & & & \\
\hline RIGHT REAR & $\mathrm{N}$ & 11,018 & 18,530 & 40,907 & & & & & \\
\hline TOTAL REACTION & $\mathrm{N}$ & 25,795 & 0 & 142,985 & TOTAL REACTION & $\mathrm{N}$ & 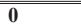 & 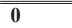 & 118,503 \\
\hline EXTERNAL LOAD & $\mathrm{N}$ & 25,796 & 0 & 142,987 & EXTERNAL LOAD & $\mathrm{N}$ & 0 & $\mathbf{0}$ & 118,513 \\
\hline ERROR & $\%$ & 0.004 & 0.000 & 0.001 & ERROR & $\%$ & 0.000 & 0.000 & 0.008 \\
\hline 3.2.2 BRAKE & \multirow{3}{*}{ UNIT } & & & & \multirow{3}{*}{$\begin{array}{l}\text { 3.1.2 BRAKE } \\
\text { CONSTRAINT NAME }\end{array}$} & \multirow{3}{*}{$U N I T$} & \multirow{2}{*}{\multicolumn{3}{|c|}{ DIRECTION }} \\
\hline \multirow[t]{2}{*}{ CONSTRAINT NAME } & & \multicolumn{3}{|c|}{ DIRECTION } & & & & & \\
\hline & & $\mathrm{X}$ & Y & $\mathrm{Z}$ & & & $\mathrm{X}$ & $\mathrm{Y}$ & $\mathrm{Z}$ \\
\hline LEFT FRONT & $\mathrm{N}$ & $-32,659$ & $-12,976$ & 41,133 & REAR AXLE & $\mathrm{N}$ & 0 & 103 & 84,308 \\
\hline RIGHT FRONT & $\mathrm{N}$ & $-32,098$ & 12,976 & 38,219 & ARTICULATION & $\mathrm{N}$ & $-31,726$ & -103 & 34,193 \\
\hline LEFT REAR & $\mathrm{N}$ & 0 & 0 & 41,543 & & & & & \\
\hline RIGHT REAR & $\mathrm{N}$ & 0 & 0 & 40,850 & & & & & \\
\hline TOTAL REACTION & $\mathrm{N}$ & $\begin{array}{l}-64,757 \\
\end{array}$ & $\overline{0}$ & 161,745 & TOTAL REACTION & $\mathrm{N}$ & $\begin{array}{l}-31,726 \\
\end{array}$ & $\begin{array}{c}\mathbf{0} \\
\end{array}$ & 118,501 \\
\hline EXTERNAL LOAD & $\mathrm{N}$ & $-64,764$ & $\mathbf{0}$ & 161,767 & EXTERNAL LOAD & $\mathrm{N}$ & $-31,735$ & $\mathbf{0}$ & 118,513 \\
\hline ERROR & $\%$ & 0.011 & 0.000 & 0.014 & ERROR & $\%$ & 0.028 & 0.000 & 0.010 \\
\hline \multirow{3}{*}{$\begin{array}{l}\text { 3.2.3 CORNERING } \\
\text { CONSTRAINT NAME }\end{array}$} & \multirow{3}{*}{ UNIT } & \multirow{2}{*}{\multicolumn{3}{|c|}{ DIRECTION }} & \multirow{3}{*}{$\begin{array}{l}\text { 3.1.3 CORNERING } \\
\text { CONSTRAINT NAME }\end{array}$} & \multirow{3}{*}{ UNIT } & \multirow{2}{*}{\multicolumn{3}{|c|}{ DIRECTION }} \\
\hline & & & & & & & & & \\
\hline & & $\mathrm{X}$ & $\mathrm{Y}$ & Z & & & $\mathrm{X}$ & $\mathrm{Y}$ & Z \\
\hline LEFT FRONT & $\mathrm{N}$ & 0 & 16,010 & 11,504 & RHS REAR AXLE & $\mathrm{N}$ & 0 & 65,934 & 81,846 \\
\hline RIGHT FRONT & $\mathrm{N}$ & 0 & 30,689 & 49,680 & LHS REAR AXLE & $\mathrm{N}$ & 0 & 5,542 & 21,292 \\
\hline LEFT REAR & $\mathrm{N}$ & 0 & 17,343 & 8123 & ARTICULATION & $\mathrm{N}$ & 0 & 19,155 & 15,363 \\
\hline RIGHT REAR & $\mathrm{N}$ & 0 & 52,678 & 73,627 & & & & & \\
\hline TOTAL REACTION & $\mathrm{N}$ & $\mathbf{0}$ & 116,720 & 142,934 & TOTAL REACTION & $\mathrm{N}$ & $\mathbf{0}$ & 90,631 & 118,501 \\
\hline EXTERNAL LOAD & $\mathrm{N}$ & $\mathbf{0}$ & 116,723 & 142,937 & EXTERNAL LOAD & $\mathrm{N}$ & $\mathbf{0}$ & 90,638 & 118,513 \\
\hline ERROR & $\%$ & 0.000 & 0.000 & 0.002 & ERROR & $\%$ & 0.000 & 0.008 & 0.010 \\
\hline 3.2.4 TORSION & \multirow{3}{*}{ UNIT } & \multirow{2}{*}{\multicolumn{3}{|c|}{ DIRECTION }} & \multirow{3}{*}{$\begin{array}{l}\text { 3.1.4 TORSION } \\
\text { CONSTRAINT NAME }\end{array}$} & \multirow{3}{*}{ UNIT } & & & \\
\hline \multirow[t]{2}{*}{ CONSTRAINT NAME } & & & & & & & & DIREC & \\
\hline & & $\mathrm{X}$ & $\mathrm{Y}$ & $\mathrm{Z}$ & & & $\mathrm{X}$ & $\mathrm{Y}$ & Z \\
\hline LEFT FRONT & $\mathrm{N}$ & 1,394 & $-3,575$ & 59,909 & REAR AXLE & $\mathrm{N}$ & $-14,424$ & 5,516 & 102,050 \\
\hline RIGHT REAR & $\mathrm{N}$ & 24,424 & 2,387 & 83,076 & ARTICULATION & $\mathrm{N}$ & 14,424 & $-5,516$ & 16,451 \\
\hline TOTAL REACTION & $\mathrm{N}$ & 25,818 & $-1,188$ & 142,985 & TOTAL REACTION & $\mathrm{N}$ & 0 & 0 & 118,501 \\
\hline EXTERNAL LOAD & $\mathrm{N}$ & 25,796 & $-1,185$ & 142,987 & EXTERNAL LOAD & $\mathrm{N}$ & $\mathbf{0}$ & $\mathbf{0}$ & 118,513 \\
\hline ERROR & \%\% & 0.085 & 0.253 & 0.001 & ERROR & \%\% & 0.000 & 0.000 & 0.010 \\
\hline
\end{tabular}

